\title{
Time to Cooling Is Associated with Resuscitation Outcomes
}

\author{
Robert B. Schock, PhD, Andreas Janata, MD, W. Frank Peacock, MD, FACEP, \\ Nathan S. Deal, MD, Sarathi Kalra, MD, MPH, and Fritz Sterz, MD²
}

Our purpose was to analyze evidence related to timing of cooling from studies of targeted temperature management (TTM) after return of spontaneous circulation (ROSC) after cardiac arrest and to recommend directions for future therapy optimization. We conducted a preliminary review of studies of both animals and patients treated with post-ROSC TTM and hypothesized that a more rapid cooling strategy in the absence of volume-adding cold infusions would provide improved outcomes in comparison with slower cooling. We defined rapid cooling as the achievement of $34^{\circ} \mathrm{C}$ within 3.5 hours of ROSC without the use of volume-adding cold infusions, with a $\geq 3.0^{\circ} \mathrm{C} /$ hour rate of cooling. Using the PubMed database and a previously published systematic review, we identified clinical studies published from 2002 through 2014 related to TTM. Analysis included studies with time from collapse to ROSC of 20-30 minutes, reporting of time from ROSC to target temperature and rate of patients in ventricular tachycardia or ventricular fibrillation, and hypothermia maintained for 20-24 hours. The use of cardiopulmonary bypass as a cooling method was an exclusion criterion for this analysis. We compared all rapid cooling studies with all slower cooling studies of $\geq 100$ patients. Eleven studies were initially identified for analysis, comprising 4091 patients. Two additional studies totaling 609 patients were added based on availability of unpublished data, bringing the total to 13 studies of 4700 patients. Outcomes for patients, dichotomized into faster and slower cooling approaches, were determined using weighted linear regression using IBM SPSS Statistics software. Rapid cooling without volume-adding cold infusions yielded a higher rate of good neurological recovery than slower cooling methods. Attainment of a temperature below $34^{\circ} \mathrm{C}$ within 3.5 hours of ROSC and using a cooling rate of more than $3^{\circ} \mathrm{C} /$ hour appear to be beneficial.

Keywords: cardiac arrest, cooling strategies, postresuscitation cooling, human studies, temperature mechanisms

\section{Introduction}

$\mathbf{P}$ ATIENT CARE GUIDELINES from the International Liaison Committee on Resuscitation (ILCOR) and the American Heart Association (AHA) (Donnino et al., 2015) recommend targeted temperature management (TTM) as a treatment for patients who are comatose after return of circulation from cardiac arrest. The newest ILCOR/AHA guidelines recommend cooling to $32-36^{\circ} \mathrm{C}$ for at least 24 hours to improve the probability of survival with favorable neurological recovery. This represents a change from the prior guidelines (ECC Committee et al., 2010), which recommended a target temperature of $32-34^{\circ} \mathrm{C}$ for $12-24$ hours. The change was largely driven by the "TTM study" (Nielsen et al., 2013), which reported similar outcomes for patients treated with $33^{\circ} \mathrm{C}$ and $36^{\circ} \mathrm{C}$ target temperatures. There is some controversy regarding the revised range of target temperatures, and some have suggested that the use of slow, late cooling in the TTM study may have decreased the therapeutic benefit of the $33^{\circ} \mathrm{C}$ target temperature (Howes et al., 2015; Polderman and Varon, 2015a).

The information that exists regarding optimal timing and depth of postresuscitation TTM is inconsistent. We conducted a meta-analysis of studies with a focus on the impact of early and rapid cooling on neurological outcomes. This analysis was designed after a preliminary review of studies including those discussed hereunder.

\footnotetext{
${ }^{1}$ Sid Wolvek Research Center, Life Recovery Systems HD, LLC, Kinnelon, New Jersey.

${ }^{2}$ Universitätsklinik für Notfallmedizin, Medizinische Universität Wien, Wien, Austria.

${ }^{3}$ Emergency Medicine, Ben Taub General Hospital, Houston, Texas.

${ }^{4}$ Baylor College of Medicine, Houston, Texas.
}

(C) Robert B. Schock, et al., 2016; Published by Mary Ann Liebert, Inc. This Open Access article is distributed under the terms of the Creative Commons License (http://creativecommons.org/licenses/by/4.0), which permits unrestricted use, distribution, and reproduction in any medium, provided the original work is properly credited. 


\section{Background}

Numerous beneficial effects and their mechanisms of action have been identified for postischemic therapeutic hypothermia, including inhibition of apoptosis and preservation of neuronal integrity (Gonzalez-Ibarra et al., 2011). In one study of pigs subjected to 10 minutes of untreated cardiac arrest followed by 8 minutes of cardiopulmonary resuscitation (CPR), 8/8 (100\%) pigs that were rapidly cooled to $32-34^{\circ} \mathrm{C}$ by surface cooling ( $\sim 5^{\circ} \mathrm{C}$ below the normal temperature of $38^{\circ} \mathrm{C}$ for this species) within 1 hour of resuscitation and rewarmed 15 hours later fully recovered by 9 days. This compared with 1/8 (12.5\%) of animals maintained at normothermia (Janata et al., 2008). Upon necropsy and histological analysis, cooling was associated with a reduction in brain cell damage. Furthermore, blood analysis (White et al., 2006) showed that, although 3 hours after resuscitation arterial neuroprotectin D1 (NPD1) increased in all animals, it was three times higher in hypothermic animals. Unlike NSE and S-100B, which are markers of injury (Calderon et al., 2014), NPD1 is an endogenous lipid mediator that reduces inflammation and apoptosis in neurons undergoing oxidative stress (Eady et al., 2012). These findings suggest that cooling beyond the 3 -hour postresuscitation window may miss an important mechanism of neuroprotection.

A similar study found that $7 / 7(100 \%)$ pigs fully recovered if they were cooled to $32-34^{\circ} \mathrm{C}$ within 2 hours of return of spontaneous circulation (ROSC) and maintained in that range for 4 hours (Yu et al., 2015). Only 3/7 (43\%) control animals that were maintained at normothermia in this study survived 4 days. This study further supported the importance of cooling within the 3-hour post-ROSC window. It also demonstrated that one of the benefits of cooling was an improvement in myocardial function during recovery and that the use of early, rapid cooling may enable the use of a shorter period of therapeutic hypothermia.

Clinical research has provided additional insight into the relationship between earlier cooling and outcomes, although this is complicated by issues related to the methods of cooling. Two randomized studies (Bernard et al., 2010; Kim et al., 2014) investigating prehospital cold intravenous fluid infusions found trends for worsened outcomes, including recurrent cardiac arrest and pulmonary edema, in resuscitated patients (Kim et al., 2014). Other analyses in which a high proportion of patients received cold infusions have likewise failed to demonstrate a benefit of earlier cooling (Nielsen et al., 2009; ICE Study Group, 2012; Debaty et al., 2014), possibly because of complications associated with this approach. The largest of these studies (Nielsen et al., 2009) may have cooled too late to have demonstrated a benefit of earlier cooling (median cooling time from arrest to $34^{\circ} \mathrm{C}$ was 260 minutes, which exceeds the 3-hour NPD1 window).

Intravenous fluid administration adds venous volume to patients, which can increase preload and decrease coronary perfusion pressure (CPP) (Yannopoulos et al., 2009). Previous work has demonstrated a correlation between CPP and ROSC (Paradis et al., 1990), with decreases associated with failed resuscitation. The observed increased incidence of rearrest associated with cold infusions (Kim et al., 2014) may likewise be related to a reduction in CPP. Therefore, when interpreting studies examining time-dependent outcomes with TTM, the potential for confounding based on the cooling method must be considered.
Comparing trials that achieved their therapeutic hypothermia target of $32-34^{\circ} \mathrm{C}$ within 2 (Bernard et al., 2002) versus 8 (HACA Study Group, 2002) hours of resuscitation yielded a proportionally higher improvement in outcomes with earlier cooling. One study of 200 postresuscitation patients found that the subset cooled to $34^{\circ} \mathrm{C}$ within 3 hours had better outcomes than those cooled later (Castrén et al., 2010). Another study of 49 postresuscitation patients found that a 1-hour delay in reaching a target temperature of $33^{\circ} \mathrm{C}$ was associated with a $31 \%$ reduction in favorable neurological recovery (Wolff et al., 2009). Furthermore, a review of 172 resuscitated patients found that every 30-minute delay in reaching $32-34^{\circ} \mathrm{C}$ was associated with a $17 \%$ increase in poor neurological outcomes (Sendelbach et al., 2012), and a related study of 140 patients found that for every 1-hour delay in the initiation of cooling, there was a $20 \%$ increase in the risk of death (Mooney et al., 2011). In another study of 171 patients, the best outcomes were achieved when the collapse to $34^{\circ} \mathrm{C}$ interval was less than 95 minutes (Nagao et al., 2010). A further study of 145 patients (Ubarri et al., 2015) found that patients who reached target temperatures of 32$33^{\circ} \mathrm{C}$ quickly had a better prognosis than those who were cooled slowly (each 1-minute delay in reaching target temperature reduced the chance of a good outcome by $0.5 \%$ ).

The advantages of faster achievement of target temperature are most apparent when adjustments are made for comorbidities; patients who have suffered more severe cerebral injury may lose the ability to conserve their own body heat and be more easily cooled (Benz-Woerner et al., 2012; Lin et al., 2014; Perman et al., 2015). A previous study that did not make such adjustments failed to demonstrate a benefit of faster achievement of target temperature (Haugk et al., 2011).

Some trials have suffered flaws that confound interpretation. Two studies (Bernard et al., 2002; HACA Study Group, 2002) allowed controls to have mild fever during recovery $\left(\sim 37.5^{\circ} \mathrm{C}\right)$. This may have worsened results in control patients and overstated the benefits of therapeutic hypothermia (hyperthermia increases ischemia-induced neurological damage) (Hindfelt, 1976).

One study (Lopez-de-Sa et al., 2012) compared $32^{\circ} \mathrm{C}$ and $34^{\circ} \mathrm{C}$ target temperatures in 36 postarrest patients. Target temperatures were typically reached 6 hours after resuscitation. The study reported better outcomes in patients who were cooled to $32^{\circ} \mathrm{C}$.

The TTM study (Nielsen et al., 2013) compared cooling targets of $33^{\circ} \mathrm{C}$ with $36^{\circ} \mathrm{C}$ in 950 patients and reported similar outcomes between cohorts. The results of the TTM study should be viewed with caution (Peacock and Deal, 2014; Howes et al., 2015; Polderman and Varon, 2015a, 2015b). Although both groups were $\sim 35^{\circ} \mathrm{C}$ at the time of enrollment (up to 4 hours after resuscitation), the target temperatures were not reached until $\sim 8$ hours later (in the $33^{\circ} \mathrm{C}$ group, $34^{\circ} \mathrm{C}$ was reached 2.5 hours postenrollment). Given how late target temperatures were reached, it is possible that the patients did not receive the potential benefits of protective mechanisms that might have been available with earlier cooling to $33^{\circ} \mathrm{C}$. If NPD1 release within the first 3 hours after cardiac arrest is necessary, it could be argued that both hypothermia target groups actually had the same level of hypothermia $\left(\approx 35^{\circ} \mathrm{C}\right)$. The animal study by Janata et al. (2008) cooled its subjects to $\approx 5^{\circ} \mathrm{C}$ below normothermia within the first 3 hours after ROSC, whereas the TTM subjects were 
only cooled to $\approx 2{ }^{\circ} \mathrm{C}$ below normothermia within this window (less than half the "dose" of hypothermia). Earlier cooling might have improved the benefits of the deeper cooling target cohort of the TTM study. This supposition is backed by an analysis (Kaneko et al., 2015) of 467 patients in whom target temperatures were reached within 3 hours of resuscitation; in this study, patients who were rapidly cooled to a temperature range of $32.0-33.5^{\circ} \mathrm{C}\left(3.5-5^{\circ} \mathrm{C}\right.$ below normothermia) had significantly better outcomes than those who were rapidly cooled to a range of $34.0-35.0^{\circ} \mathrm{C}\left(2-3^{\circ} \mathrm{C}\right.$ below normothermia).

On this basis, we hypothesized that a rapid cooling approach in which patients are cooled to a temperature below $34^{\circ} \mathrm{C}$ within the first 3.5 hours after resuscitation using a high speed of cooling (to enhance therapeutic effects such as NPD1 release) and avoiding the use of volume-adding cold intravenous infusions (to minimize the harmful effects of increased venous volume) would yield superior outcomes compared with the use of slower cooling approaches with or without cold infusions.

\section{Methods}

\section{Search strategy}

Our meta-analysis examined both randomized and observational studies of the use of therapeutic hypothermia in postresuscitation patients and was conducted following the MOOSE guidelines for meta-analysis of observational studies (Stroup et al., 2000). We performed a systematic review of the literature related to therapeutic hypothermia and resuscitation, as summarized in Appendix 1. This included a search of the PubMed database for studies in English published from January 1, 2012, to January 1, 2015, using the search terms "therapeutic hypothermia" OR "temperature management" AND "cardiac arrest OR resuscitation." In addition, we examined all of the studies cited in a previous systematic review (Walters et al., 2014). We contacted several authors in an effort to include all available studies.

\section{Selection of studies for inclusion in meta-analysis}

The selection of study inclusion criteria was based on examination of the largest published studies of postresuscitation therapeutic hypothermia. Inclusion criteria included documentation of time delay from collapse to ROSC of 20-30 minutes, reporting of the time delay from ROSC to target temperature, percentage of patients in ventricular tachycardia (VT) or ventricular fibrillation (VF), and therapeutic hypothermia maintained for 20-24 hours. Studies were excluded from numerical analysis if they used cardiopulmonary bypass, did not include time delay from ROSC to target temperature, did not report age, excluded patients $>65$ years, did not report CPC (Cerebral Performance Categories) scores (Safar, 1981), did not report time interval from collapse to ROSC, did not cool all patients, or excluded patients who died during therapeutic hypothermia.

We sought to analyze results to investigate whether differences in outcomes could be detected between rapid and slower cooling studies. We defined rapid cooling studies as those in which a core temperature of $34^{\circ} \mathrm{C}$ was reached within 3.5 hours of ROSC without the use of cold volume-adding intravenous infusions, with a $\geq 3.0^{\circ} \mathrm{C} /$ hour rate of core body cooling. Because few studies of rapid cooling are available, all are included regardless of size. However, because so many slow cooling studies are available, only slow cooling studies with $>100$ patients enrolled are included in this analysis.

\section{Data extraction and analysis}

The abstract of each study identified in the search was screened for inclusion/exclusion criteria. If necessary for screening, the full article was reviewed. Study exclusion criteria were identified and tabulated for all citations. Results from included studies were taken directly from each publication and tabulated, including number of patients, time from cardiac arrest to ROSC, patient age, cooling methods, time from ROSC to target temperature, percentage of patients with VT/VF rhythms, and percentage of patients with good outcomes (CPC 1 or 2 ). Cooling rates in ${ }^{\circ} \mathrm{C} /$ hour were tabulated as reported, or if unreported were calculated from the published study data. Percentages of patients recovering with favorable outcomes were determined for VT/VF and nonVT/VF patients using weighted linear regression analysis (weighted by number of patients in each study) using IBM SPSS Statistics software (Version 22); this analysis was performed for both the rapid and slower cooling study groups. As additional exploratory analyses, we examined speed of cooling and time to target as independent predictors of outcome in post-VT/VF patients.

\section{Results}

Our search strategy, as summarized in Figure 1, identified 751 articles, of which 594 were excluded based on review of abstracts, leaving 157 articles for review. One hundred fortysix of these were excluded based on the criteria shown in Figure 1. Three rapid cooling studies and 8 slower cooling studies comprising 4091 patients were identified by the preliminary search. Two additional studies were added to the analysis after unpublished information was made available by the study authors [these were a slower cooling study (Drennen et al., 2014) and a rapid cooling study (Kudagi et al., 2012)]. This yielded 13 studies comprising a total of 4700 patients. Cooling methods were then dichotomized into relative "speed of cooling cohorts" and consisted of the four clinical trials of rapid cooling with a reported average time from ROSC to target temperature of 2.5 hours and average cooling rate of $4.4^{\circ} \mathrm{C} /$ hour, and nine slower cooling studies, with a reported average time from ROSC to target temperature of 4.9 hours and average cooling rate of $0.6^{\circ} \mathrm{C} /$ hour (Table 1). Patient ages in the two cohorts were similar $(61.3$ and 62.8 years) and the two groups had a similar delay from cardiac arrest to ROSC (23.5 and 22.4 minutes).

The outcomes of patients from the rapid cooling studies were superior to those from the slower cooling studies (Fig. 2). The advantage of faster cooling was more pronounced for VT/VF patients than for non-VT/VF patients. Further analysis of the VT/VF patient data suggests that the chances of favorable outcomes for these patients may be linearly related to the rate of cooling (Fig. 3A), with a cooling rate more than $3^{\circ} \mathrm{C} /$ hour yielding the best results. Time delays from ROSC to $34^{\circ} \mathrm{C}$ ranging from 4 to 8 hours appear to produce similar outcomes, but a delay of shorter than 3 hours may contribute to improved outcomes (Fig. 3B). 


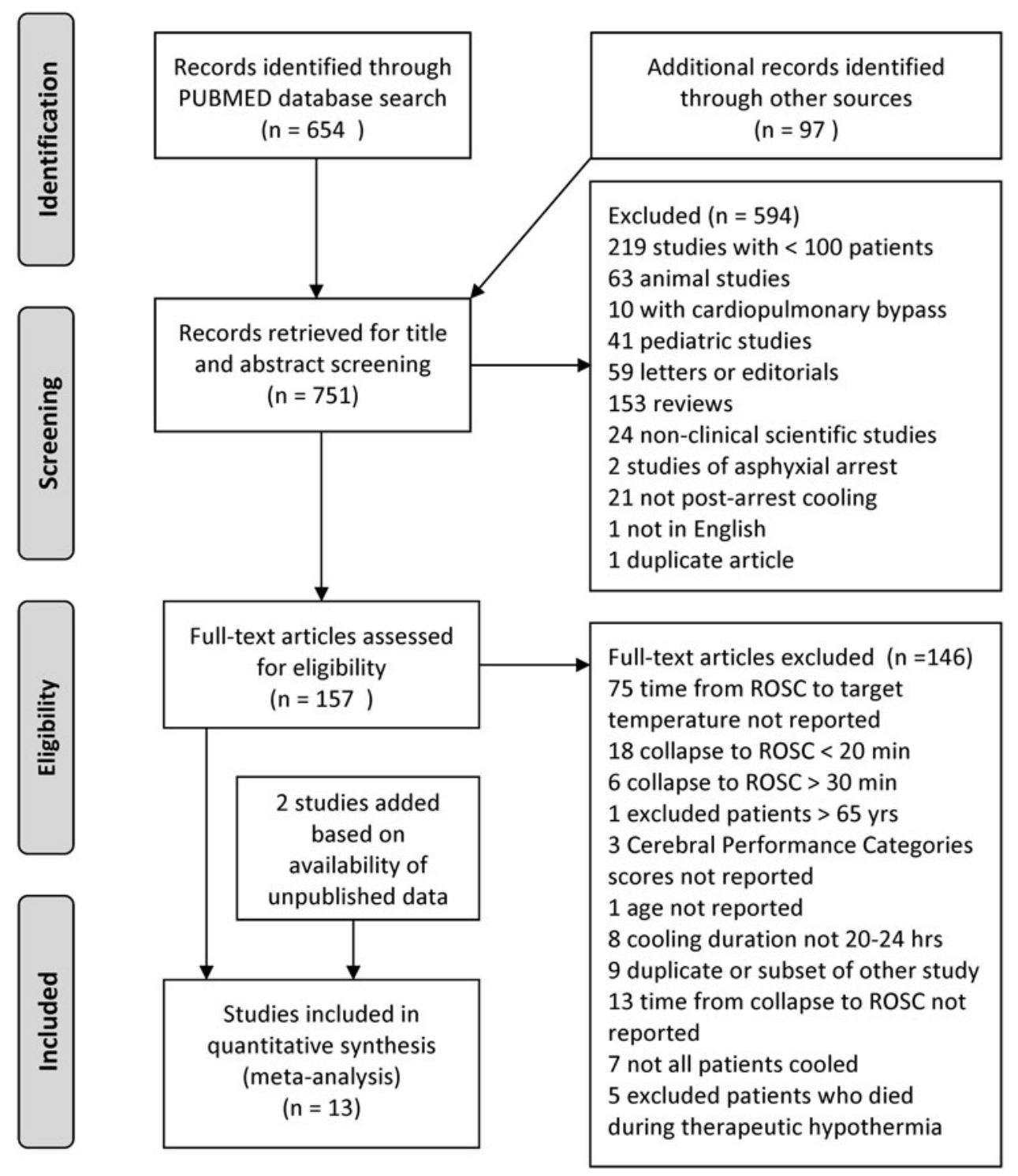

FIG. 1. Study selection flow diagram.

\section{Discussion}

\section{Summary of evidence}

Our meta-analysis examining the time dependency of cooling in 4700 patients suggests that early and rapid cooling without the use of cold infusions is associated with superior outcomes as compared with delayed cooling or cold saline volume resuscitation. Although further prospective studies are needed, our evaluation also suggests that rapid cooling to $32-34^{\circ} \mathrm{C}$ is associated with superior outcomes as compared with delayed cooling to any temperature. The physiology supporting these findings is consistent with previous basic science laboratory work, early laboratory biomarker investigations, and the confounding associated with cold saline volume resuscitation.

\section{Risks of bias}

A key potential source of bias in the comparison of postresuscitation studies is the influence of cardiac arrest rhythm on outcome. Numerous sources have documented that pa- tients with VT/VF rhythms generally have a better prognosis than those with nonshockable rhythms (Kim et al., 2014; Walters et al., 2014). This makes it challenging to compare studies in which outcomes are not broken down by cardiac rhythms. For this reason, we analyzed outcome data as a function of the percentage of shockable rhythms in each study using a weighted linear regression analysis.

Other potential sources of bias include patient age and delay from collapse to ROSC. Both higher patient age and a longer delay to ROSC are known to worsen outcomes. The studies utilized in our analysis were well matched in these areas, which we believe eliminated the risk of this type of bias.

Our search uncovered only four small studies that met both our definition of rapid cooling and fell within our acceptance criteria, totaling 79 patients. A 200-patient randomized study (Castrén et al., 2010) demonstrated a trend for improved outcomes with earlier cooling (target reached within 2.1 hours of ROSC), but this study employed a cooling rate of only $0.7^{\circ} \mathrm{C} /$ hour. It was not included in our regression analysis because of its relatively long delay to ROSC (31 minutes). This study reported lower rates of recovery for patients 


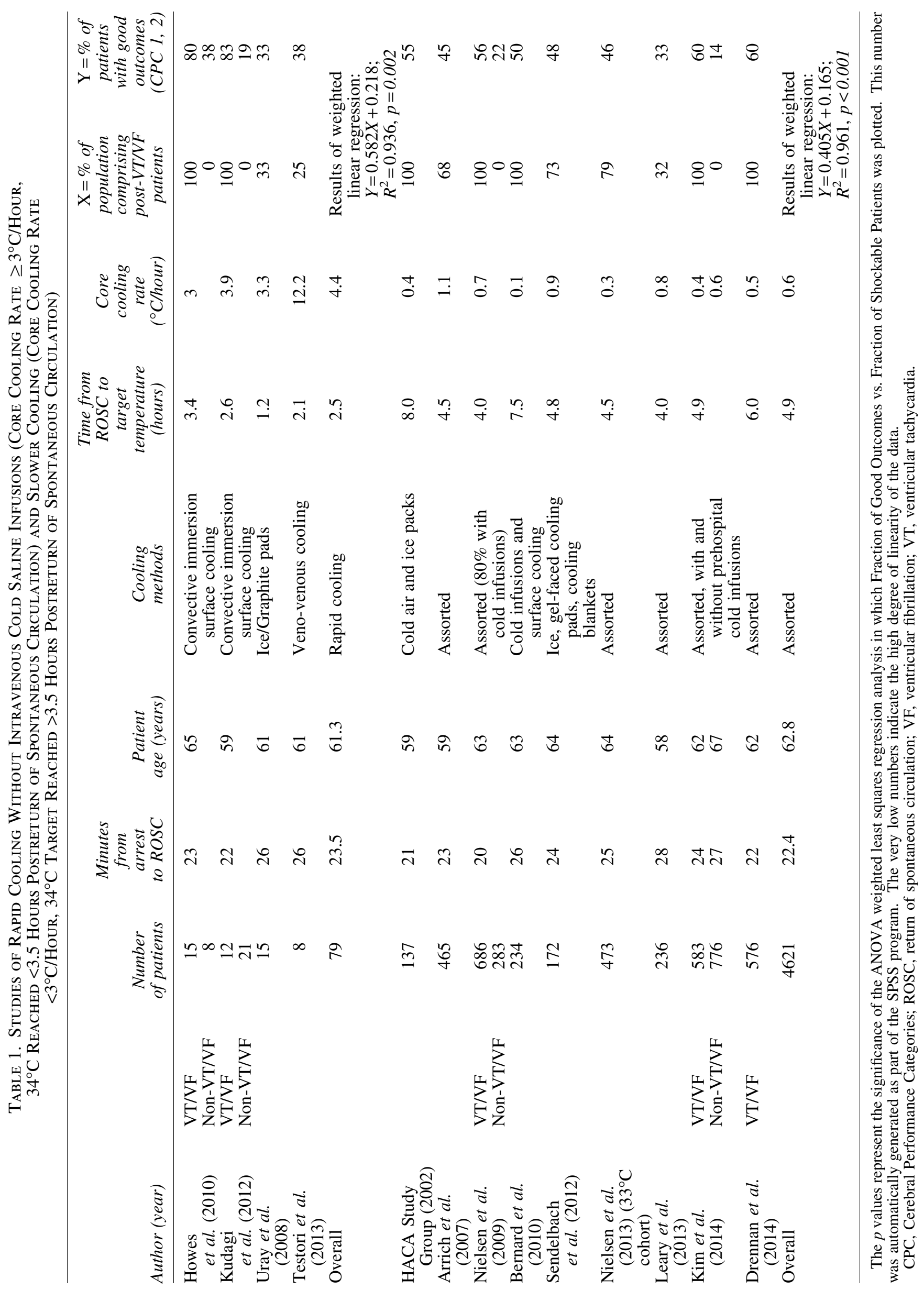




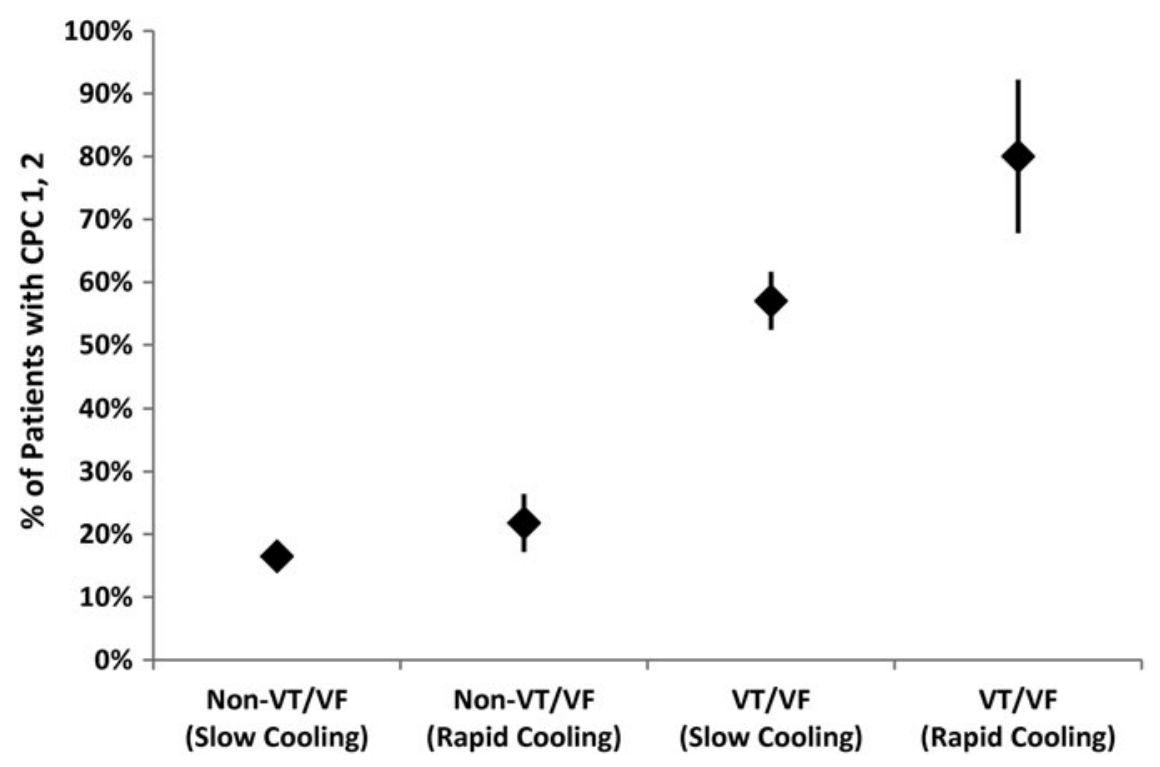

FIG. 2. Rates of favorable recovery (CPC 1 or 2) (Safar, 1981) versus Cardiac Arrest Rhythm (Clinical Studies of PostResuscitation Cooling) as predicted by weighted linear regression analysis of clinical studies listed in Table 1 (weighted by number of patients in studies). Standard errors, indicated by the vertical lines, do not overlap for VT/VF rhythms, suggesting an advantage of the faster cooling approach for patients resuscitated from shockable rhythms. CPC, Cerebral Performance Categories; VF, ventricular fibrillation; VT, ventricular tachycardia.

in general (whether treated with rapid or slow cooling) than were seen in comparable studies having shorter delays to ROSC. It has elsewhere been reported that a delay to ROSC of more than 29 minutes reduces the benefits of TTM (Wallmuller et al., 2016).
Two of the rapid cooling studies included in the analysis were conducted using a cooling device marketed by the company that employs one of the authors (R.B.S.). The risk of bias from the use of these studies is judged to be small. One of these studies (Howes et al., 2010) was conducted at three

\begin{tabular}{|c|c|c|c|c|}
\hline Study & $\begin{array}{c}\text { Number of VT/VF } \\
\text { Patients }\end{array}$ & Cooling Rate $\left(\mathrm{C}^{\circ} \mathrm{hr}\right)$ & $\begin{array}{c}\text { Delay from ROSC to } \\
\text { Target (hours) }\end{array}$ & $\%$ of Patients with Favorable Recovery (CPC 1,2$)$ \\
\hline Kudagi et al ., 2012 & 12 & 3.90 & 2.6 & $83 \%$ \\
\hline Howes et al ., 2010 & 15 & 3.00 & 3.4 & $80 \%$ \\
\hline Drennan et al., 2014 & 576 & 0.50 & 6 & $60 \%$ \\
\hline Nielsen et al., 2009 & 686 & 0.70 & 4 & $56 \%$ \\
\hline Kimet al ., 2014 & 583 & 0.40 & 4.9 & $60 \%$ \\
\hline Holzer et al ., 2002 & 137 & 0.40 & 8 & $55 \%$ \\
\hline Bernard et al ., 2010 & 234 & 0.10 & 7.5 & $50 \%$ \\
\hline Total & 2243 & & & \\
\hline
\end{tabular}

A

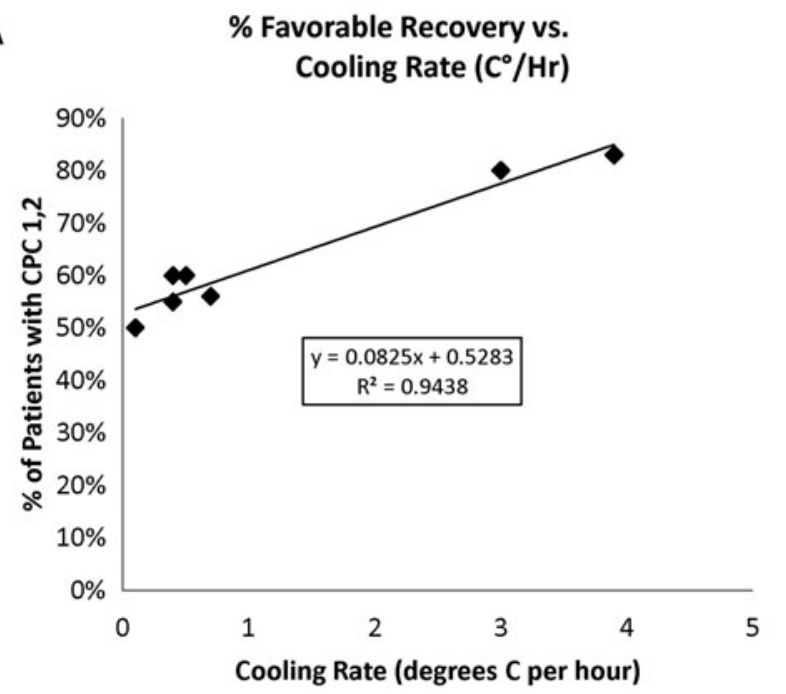

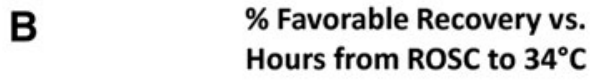

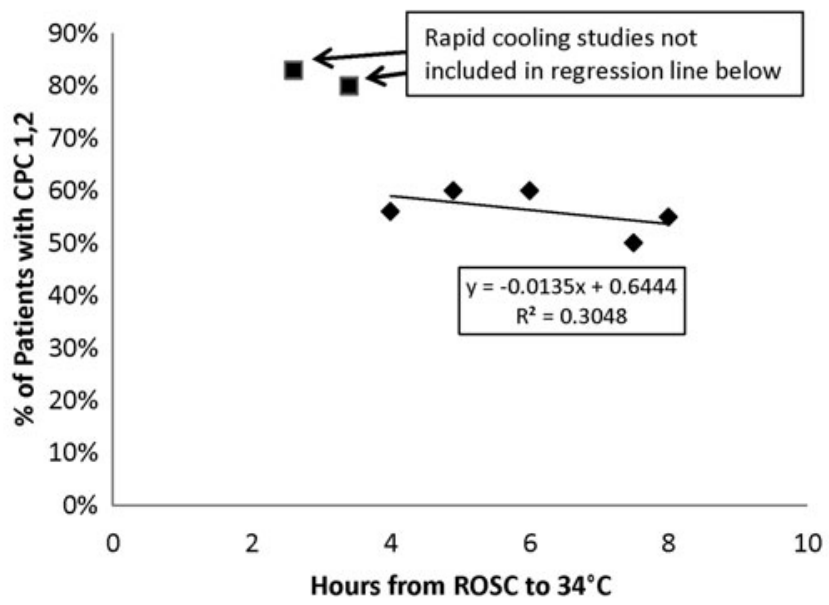

FIG. 3. Exploratory linear regression analyses of clinical studies showing chances of good outcomes (CPC 1 or 2) (Safar, $1981)$ of post-VT/VF patients treated with targeted temperature management versus $(\mathbf{A})$ cooling speed $\left({ }^{\circ} \mathrm{C} /\right.$ hour $)$ and $(\mathbf{B})$ time delay from ROSC to target (hours). Regression line in plot (A) includes both rapid and slower cooling studies. Regression line in plot (B) includes only slower cooling studies; faster cooling studies in this plot are shown as boxes. ROSC, return of spontaneous circulation. 
hospitals under Good Clinical Practices guidelines (Food and Drug Administration, 1997), with results audited and verified by an independent clinical research organization. The second of these studies, a single-center study of the same device (Kudagi et al., 2012), was conducted independently by physicians at the Ochsner Research Foundation (New Orleans, LA) without the involvement of the company and produced similar results. The inclusion of this study did not markedly impact the average outcomes for rapid cooling, but it did reduce the standard error.

The disparate sizes of clinical studies could have introduced bias. We sought to minimize this bias by performing an analysis that was weighted by the number of patients in each study. This weighted approach was applied to all key variables, including patient ages, delay to ROSC, and the linear regression analysis of outcomes. We only included studies of 100 or more patients in the slow-cooling group, which may give the appearance of selection bias when compared with the selection of smaller rapid cooling studies. However, exploratory analyses in which we also included smaller studies of slow cooling produced the same line of regression with little change in the standard error. The largest six studies, which totaled 3842 patients, dominated the weighted linear regression results for slow cooling.

\section{Quality of included studies}

The meta-analysis used results from a mixture of mediumto high-quality prospectively randomized studies (HACA Study Group, 2002; Bernard et al., 2010; Nielsen et al., 2013; Kim et al., 2014) and those from nonrandomized studies. Most of the nonrandomized slow-cooling studies corresponded closely to the mean line of regression that was shared with the slow-cooling randomized studies, an observation that supports this approach.

\section{Impact of cooling rate}

A comparison of the effects of cooling rate (Fig. 3A) and time to target (Fig. 3B) suggests that a high cooling rate may be beneficial independently of time from ROSC to target. Rapid cooling induction reduces the length of time during which the patient is exposed to potentially harmful effects of the cooling process, such as metabolic disorders and shivering; shivering is typically reduced at core body temperatures below $\sim 33.5^{\circ} \mathrm{C}$ (Polderman and Herold, 2009). A further potential source of cooling-induced physiological stress is nonshivering thermogenesis originating in brown adipose tissue (BAT); this has been reported to cause a 1.8-fold increase in whole-body energy expenditure lasting 3 hours or more in adult humans (Ouellet et al., 2012). Research in anesthetized rats suggests that BAT sympathetic nerve activity and thermogenesis are substantially reduced when core body temperature drops to $\sim 33^{\circ} \mathrm{C}$ (Christopher J. Madden, Oregon Health and Science University, Portland, OR, unpublished information). The largest study of prehospital cold infusions (Kim et al., 2014) found that patients receiving prehospital cooling arrived at the hospital at a temperature of $35^{\circ} \mathrm{C}$, whereas those not receiving prehospital cooling were nearly $1^{\circ} \mathrm{C}$ higher. The patients receiving prehospital cooling had statistically lower $\mathrm{pH}, \mathrm{PaO}_{2}, \mathrm{SaO}_{2}$, and glucose, suggesting that this treatment created additional, potentially stressful metabolic activity. This may have contributed to the elevated rate of recurrent cardiac arrest in this group. A higher rate of cooling, by dropping temperature more rapidly to a level below $33^{\circ} \mathrm{C}$, might reduce the stress of the cooling induction process.

\section{Impact of time from ROSC to target}

Figure 3B shows a nonlinear relationship between outcomes and time to target. The results suggest that outcomes are very similar over the 4-8 hour range of time delay from ROSC to target. A number of studies in which target temperatures were reached beyond the 4 hour window have reported a lack of correlation between outcome and time to target (Nielsen et al., 2009; Kim et al., 2014). This is also consistent with analysis of the TTM study data, which found no signal supporting an advantage of faster cooling (Della Mattia et al., 2015). Our analysis suggests a stepwise improvement in outcomes for times to target below 3 hours, supporting the theory that there is an improved activation of neuroprotective mechanisms if cooling induction is completed within this window. Only a small proportion of patients in the TTM study were cooled to the $33^{\circ} \mathrm{C}$ level within the 3-hour window (Nielsen et al., 2013).

\section{Limitations}

Our report represents an analysis of multiple studies, and although its size suggests that the identified trends are robust, the presence of significant uncontrolled and unidentified confounders cannot be excluded. Furthermore, the lack of any large rapid cooling investigations may result in an excessive reliance in our analysis on a minority population. Nevertheless, our data suggest that, consistent with many other critical interventions (e.g., glucose for hypoglycemia or oxygen for hypoxia), a time-dependent relationship with outcomes is likely. We suggest that further studies investigating therapeutic hypothermia should report the time interval from the ROSC until target temperature has been reached, as well as the rate of cooling induction.

\section{Conclusions}

The optimal timing and depth of therapeutic hypothermia for postresuscitation patients remain unknown. The value of rapid cooling for victims of cardiac arrest is supported by animal data showing improved outcomes and enhanced release of the neuroprotective lipid mediator NPD1 when rapid cooling is provided within the first 3 hours after resuscitation, and this is further supported by regression analysis of prior clinical studies. Our preliminary analysis suggests that a more rapid rate of cooling may be beneficial in its own right. Analyses of some clinical studies also suggest that deeper cooling may be beneficial, but this is confounded by patientand treatment-related variables, including the timing of cooling and the use of cold intravenous infusions. We recommend that additional randomized studies be conducted to investigate the impact of rapid cooling treatments on the neurological outcomes of postresuscitation patients. Additional knowledge regarding the value of faster and/or deeper cooling may be gained by measuring the release of NPD1 and other markers of neurological recovery in humans, as well as metabolic indicators related to the physiological stresses of the cooling process. 


\section{Acknowledgments}

We are grateful to Ian Drennan and Steve Lin for providing unpublished information related to the timing of cooling in their study, to Drs. Vinad Kudagi, Paul McMullan, and Christopher White for permission to publish the results of their study, and to Dr. Christopher Madden for sharing his unpublished observations regarding BAT thermogenesis.

\section{Authors' Contributions}

Electronic search was conducted by author R.B.S. (PhD) and additional hand search was conducted by authors W.F.P., N.S.D., A.J., and F.S. (all MDs with experience in emergency medical research). Author S.K., also an MD, contributed professional statistical expertise. All authors contributed to the writing and revision of the article.

\section{Author Disclosure Statement}

Dr. Schock is employed by and owns stock in Life Recovery Systems HD, LLC. The Department of Emergency Medicine of the Medical University of Vienna, which employs Drs. Sterz and Janata, has received research grants from Alsius, KCI Medical, Medivance, Inc., Life Recovery Systems, Benechill, Inc. and Medcool, Inc. Dr. Peacock has received research grants from Abbott, Alere, Brahms, Novartis, Roche, The Medicine's Company; is a consultant of Abbott, Alere, BG Medicine, Cardiorentis, GE, Jannsen, Lily, The Medicine's Company, Singulex, Verathon; and has ownership interest for Comprehensive Research Associates LLC, Vital Sensors, Emergencies in Medicine LLC. Dr. Deal has received research grants from Cardiorentis, Alere, Novartis, and is a consultant of Alere, BGMedicine, GE, and Thermo Fisher. Dr. Kalra has no conflicts to disclose. This study was funded by Life Recovery Systems HD, LLC. The company's patient cooling device was developed with the assistance of funding from the National Heart, Lung, and Blood Institute of the National Institutes of Health under grant number 5R44HL072542-03.

\section{References}

Arrich J. European Resuscitation Council Hypothermia After Cardiac Arrest Registry Study Group: Clinical application of mild therapeutic hypothermia after cardiac arrest. Crit Care Med 2007;35:1041-1047.

Bernard SA, Gray TW, Buist MD, et al. Treatment of comatose survivors of out-of-hospital cardiac arrest with induced hypothermia. N Engl J Med 2002;346:557-563.

Bernard SA, Smith K, Cameron P, et al. Induction of therapeutic hypothermia by paramedics after resuscitation from out-of-hospital ventricular fibrillation cardiac arrest. A randomized controlled trial. Circulation 2010;122:737-742.

Benz-Woerner J, Delodder F, Benz R, et al. Body temperature regulation and outcome after cardiac arrest and therapeutic hypothermia. Resuscitation 2012;83:338-342.

Calderon LM, Guyette FX, Doshi AA, Callaway CW, Rittenberger JC; Post Cardiac Arrest Service. Combining NSE and S100B with clinical examination findings to predict survival after resuscitation from cardiac arrest. Resuscitation 2014;85: 1025-1029.

Castrén M, Nordberg P, Svensson L, et al. Intra-arrest transnasal evaporative cooling. A randomized, prehospital, multicenter study (PRINCE: Pre-ROSC IntraNasal Cooling Effectiveness). Circulation 2010;122:729-736.

Debaty G, Maignan M, Savary D, et al. Impact of intra-arrest therapeutic hypothermia in outcomes of prehospital cardiac arrest: A randomized trial. Intensive Care Med 2014;40: 1832-1842.

Della Mattia A, Pellis T, Gregori D, Nielsen N, Campanile V, Peratoner A, Brunetti I, Pelosi P, Kjaergaard J, Hassager C. Time to target temperature and outcome after out-of-hospital cardiac arrest [Abstract]. Circulation 2015;132:A13943.

Donnino MW, Anderson LW, Berg KM, et al. Temperature management after cardiac arrest: An advisory statement by the Advanced Life Support Task Force of the International Liaison Committee on Resuscitation and the American Heart Association Emergency Cardiovascular Care Committee and the Council on Cardiopulmonary, Critical Care, Perioperative and Resuscitation. Circulation 2015;132:2448-2456.

Drennan IR, Lin S, Thorpe KE, et al. The effect of time to defibrillation and targeted temperature management on functional survival after out-of-hospital cardiac arrest. Resuscitation 2014;85:1623-1628.

Eady T, Belyev L, Khoutorova L, Atkins KD, Zhang C, Bazan NG. Docosahexaenoic acid signaling modulates cell survival in experimental ischemic stroke penumbra and initiates longterm repair in young and aged rats. PLoS One 2012;7:e46151.

ECC Committee, Subcommittees and Task Forces of the American Heart Association: 2010 American Heart Association. Guidelines for Cardiopulmonary Resuscitation and Emergency Cardiovascular Care. Circulation 2010;122:S768S786.

Food and Drug Administration. ICH Topic E6: Good Clinical Practice Guidelines. Guidance for Industry. E6 Good Clinical Practice: Consolidated Guidance. 62 Federal Register 25692. Available at: www.ich.org/cache/compos/276-254-1.html accessed May 9, 1997.

Gonzalez-Ibarra FP, Varon J, Lopez-Meza EG. Therapeutic hypothermia: Critical review of the molecular mechanisms of action. Front Neurol 2011;2:1-8.

Haugk M, Testori C, Sterz F, et al. Relationship between time to target temperature and outcome in patients treated with therapeutic hypothermia after cardiac arrest. Crit Care 2011; 15:R101.

Hindfelt B. The prognostic significance of subfebrility and fever in ischemic cerebral infarction. Acta Neurol Scand 1976;53: 72-79.

Howes D, Gray SH, Brooks SC, Boyd JG, Djogovic D, Golan E, Green RS, Jacka MJ, Sinuff T, Chaplin T, Smith OM, Owen J, Szulewski A, Murphy L, Irvine S, Jichici D, Muscedere J. Canadian guidelines for the use of targeted temperature management (therapeutic hypothermia) after cardiac arrest: A joint statement from The Canadian Association of Emergency Physicians (CAEP), the Canadian Critical Care Society (CCCS), Canadian Neurocritical Care Society (CNCCS), and the Canadian Critical Care Trials Group (CCCTG). Resuscitation 2015;98:48-63.

Howes D, Ohley W, Dorian P, et al. Rapid induction of therapeutic hypothermia using convective-immersion surface cooling: Safety, efficacy, and outcomes. Resuscitation 2010;81: 388-392.

Hypothermia after Cardiac Arrest (HACA) Study Group. Mild Therapeutic Hypothermia to Improve the Neurologic Outcome after Cardiac Arrest. N Engl J Med 2002;346:549-556.

ICE Study Group. Early- versus late-initiation of therapeutic hypothermia after cardiac arrest: Preliminary observations from 
the experience of 17 Italian intensive care units. Resuscitation 2012;83:823-828.

Janata A, Weihs W, Bayegan K, et al. Therapeutic hypothermia with a novel surface cooling device improves neurologic outcome after prolonged cardiac arrest in swine. Crit Care Med 2008;36:895-902.

Kaneko T, Kasaoka S, Nakahara T, et al. Effectiveness of lower target temperature therapeutic hypothermia in post-cardiac arrest syndrome patients with a resuscitation interval of $\leq 30 \mathrm{~min}$. J Intensive Care 2015;3:28.

Kim F, Nichol G, Maynard C, Hallstrom A, et al. Effect of prehospital induction of mild hypothermia on survival and neurological status among adults with cardiac arrest-A randomized trial. JAMA 2014 311:45-52.

Kudagi V, McMullan P, White C. Rapid induction of therapeutic hypothermia in comatose survivors of cardiac arrest using liquid-convection immersion cooling [Abstract]. Presented at The Society for Cardiovascular Angiography and Intervention's $35^{\text {th }}$ Annual Scientific Sessions, May 9-12, Las Vegas, NV. SCAI 2012.

Leary M, Grossestreuer AV, Iannacone S, et al. Pyrexia and neurologic outcomes after therapeutic hypothermia for cardiac arrest. Resuscitation 2013;84:1056-1061.

Lin S, Scales DC, Dorian P, et al. Targeted temperature management processes and outcomes after out-of-hospital cardiac arrest: An observational cohort study. Crit Care Med 2014; 42:2565-2574

Lopez-de-Sa E, Rey JR, Armada E, et al. Hypothermia in comatose survivors from out-of-hospital cardiac arrest: Pilot trial comparing 2 levels of target temperature. Circulation 2012; 126:2826-2833.

Mooney MR, Unger BT, Boland LL, et al. Therapeutic hypothermia after out-of-hospital cardiac arrest: Evaluation of a regional system to increase access to cooling. Circulation 2011;124:206-214.

Nagao K, Kikushima K, Watanabe K, et al. Early induction of hypothermia during cardiac arrest improves neurological outcomes in patients with out-of-hospital cardiac arrest who undergo emergency cardiopulmonary bypass and percutaneous coronary intervention. Circ J 2010;74:77-85.

Nielsen N, Hovdenes J, Nilsson F, et al. Outcome, timing, and adverse events in therapeutic hypothermia after out-ofhospital cardiac arrest. Acta Anesthesiol Scand 2009;53:926934.

Nielsen N, Wetterslev J, Cronberg T, et al. Targeted temperature management at $33^{\circ} \mathrm{C}$ versus $36^{\circ} \mathrm{C}$ after cardiac arrest. $\mathrm{N}$ Engl J Med 2013;369:2197-2206.

Ouellet V, Labbé SM, Blondin DP, et al. Brown adipose tissue oxidative metabolism contributes to energy expenditure during acute cold exposure in humans. J Clin Invest 2012; 122:545-552.

Paradis NA, Martin GB, Rivers EP, et al. Coronary perfusion pressure and the return of spontaneous circulation in human cardiopulmonary resuscitation. JAMA 1990;263:1106-1113.

Peacock WF, Deal NS. Is time to cooling target temperature important? Crit Pathw Cardiol 2014;13:82-83.

Perman SM, Ellenberg JH, Grossestreuer AV, et al. Shorter time to target temperature is associated with poor neurologic outcome in post-arrest patients treated with targeted temperature management. Resuscitation 2015;88C:114-119.
Polderman K, Herold I. Therapeutic hypothermia and controlled normothermia In the intensive care unit: Practical considerations, side effects, and cooling methods. Crit Care Med 2009;37:1101-1120.

Polderman KH, Varon J. How low should we go? Circulation 2015a;131:669-675.

Polderman KH, Varon J. Interpreting the results of the targeted temperature management trial in cardiac arrest. Ther Hypothermia Temp Manag 2015b;5:1.

Safar P. Resuscitation after brain ischemia. In: Brain Failure and Resuscitation. Grenvik A, Safar P (eds). New York, NY: Churchill Livingstone, 1981, pp. 155-184.

Sendelbach S, Hearst MO, Johnson PJ, et al. Effects of variation in temperature management on cerebral performance category scores in patients who received therapeutic hypothermia post cardiac arrest. Resuscitation 2012;83:829-834.

Stroup DF, Berlin JA, Morton SC. Meta-analysis of observational studies in epidemiology-A proposal for reporting. JAMA 2000;283:2008-2012.

Testori C, Holzer M, Sterz F, et al. Rapid induction of mild therapeutic hypothermia by extracorporeal veno-venous blood cooling in humans. Resuscitation 2013;84:1051-1055.

Ubarri A, Bueno H, Pérez-Castellanos A, et al. Impact of time to cooling initiation and time to target temperature in patients treated with hypothermia after cardiac arrest. Eur Heart J Acute Cardiovasc Care 2015;4:365-372.

Uray T, Malzer R. Vienna Hypothermia After Cardiac Arrest (HACA) Study Group: Out-of-hospital surface cooling to induce mild hypothermia in human cardiac arrest: A feasibility trial. Resuscitation 2008;77:331-338.

Wallmuller C, Testori C, Sterz F, et al. Limited effect of mild therapeutic hypothermia on outcome after prolonged resuscitation. Resuscitation 2016;98:15-19.

Walters JH, Morley PT, Nolan JP. The role of hypothermia in post-cardiac arrest patients with return of spontaneous circulation: A systematic review. Resuscitation 2014;82:508-516.

White CJ, Marcheselli VL, Janata A, et al. Lipid mediators as novel biomarkers and surrogate indicators of neurologic recovery after cardiac arrest in a hypothermic swine model [Abstract]. Circulation 2006;73:s114:II_1203.

Wolff B, Machill K, Schumacher D, et al. Early achievement of mild therapeutic hypothermia and the neurologic outcome after cardiac arrest. Int J Cardiol 2009;133:223-229.

Yannopoulos D, Zvman M, Castro V, et al. Intra-cardiopulmonary resuscitation hypothermia with and without volume loading in an ischemic model of cardiac arrest. Circulation 2009;120: 1426-1535.

Yu T, Yang Z, Li H, Ding Y, Huang Z, Li Y. Short duration combined mild hypothermia improves resuscitation outcomes in a porcine model of prolonged cardiac arrest. Biomed Res Int 2015;2015:279192.

Address correspondence to: Robert B. Schock, PhD Sid Wolvek Research Center Life Recovery Systems HD, LLC 170 Kinnelon Road, Suite 5 Kinnelon, NJ 07405

E-mail: bschock@life-recovery.com 


\section{Appendix. PUBMED Search Strategy}

Search conducted January 21, 2015 on www.ncbi.nlm.nih.gov/pubmed/advanced All fields: "therapeutic hypothermia" OR "temperature management"

AND All fields: "cardiac arrest" OR "resuscitation"

AND Date of Publication: From January 01, 2012 to January 01, 2015

AND Language: English

Result: 654 citations (included 1 duplicate)

Net: 653 citations available for selection 